\title{
RELAÇÕES DE INDEPENDÊNCIA E DEPENDÊNCIA FUNCIONAL ENTRE OS OPERANTES VERBAIS MANDO E TATO COM A MESMA TOPOGRAFIA.
}

\author{
FUNCTIONAL INDEPENDENCE AND DEPENDENCE RELATIONS BETWEEN MAND \\ AND TACT WITH THE SAME TOPOGRAPHY
}

\author{
LuCAS FerRaz Córdova ${ }^{1}$
}

UNIVERSIDADE FEDERAL DE MATO GROSSO DO SUL E UNIVERSIDADE DE BRASÍLIA, BRASIL

\author{
Mariana Lage e Antonio de Freitas Ribeiro \\ UNIVERSIDADE DE BRASÍLIA, BRASIL
}

\begin{abstract}
RESUMO
O presente estudo buscou investigar se o ensino de uma topografia de resposta verbal em um determinado operante é suficiente para produzir a emissão dessa mesma topografia em outro operante verbal. Buscou ainda investigar se a ordem de treino (i.e. treino de mando - teste de surgimento colateral de tato; treino de tato - teste de surgimento colateral de mando) exerce alguma diferença sobre o desempenho dos participantes. Participaram do estudo 10 crianças divididas em dois grupos diferenciados pela ordem de treino. O Grupo 1 começou com o treino de mando e teste de tato, enquanto que o Grupo 2 iniciou o procedimento com treino de tato e teste de mando. $\mathrm{O}$ Grupo 1 era composto por quatro crianças e o Grupo 2 por seis crianças. Foi observado um padrão de independência funcional nas crianças do Grupo 2, já no Grupo 1 foi possível identificar padrões de independência e de dependência funcional entre mandos e tatos. Os dados são discutidos levando em consideração a noção de controle de estímulos, e ainda, apresenta uma visão dinâmica da mudança de independência para a dependência funcional.
\end{abstract}

Palavras-chave: comportamento verbal, operantes verbais, tato, mando, independência funcional

\begin{abstract}
The present study investigated if training a certain verbal response topography in one operant was sufficient to produce the emergence of this same topography in another verbal operant. It also investigated if the order of training (i.e. mand training - collateral emergence of tact testing; tact training - collateral emergence of mand testing) affected participants' performances. Ten children participated in the study and were divided into two experimental groups based on order of training. Group 1, with four children, started with mand training and tact testing, while Group 2, with six children, started with tact training and mand testing. The results showed a pattern of function independence with the children of Group 2, while it was possible to observe both functional independence and dependence between mands and tacts with the children in Group 1. The results are discussed based on stimulus control and present a dynamic view of the change from independence to functional dependence.
\end{abstract}

Key words: verbal behavior, verbal operant, tact, mand, functional independence

Skinner (1957) define comportamento verbal como todo e qualquer comportamento em que a conseqüência é mediada por um ouvinte treinado a responder a estímulos verbais por uma comunidade verbal. Comportamento verbal se enquadraria, então, dentro do paradigma operante. Sendo assim, princípios básicos como modelagem, discriminação, extinção, generalização seriam aplicáveis tam- bém ao comportamento verbal. Como todo e qualquer comportamento, o comportamento verbal tem como suas variáveis controladoras o contexto no qual é emitido e pelo menos ocasionalmente é reforçado. Dessa forma, a análise do comportamento verbal deve ater-se às variáveis ambientais controladoras, indicando assim a sua função. O comportamento verbal foi categorizado por Skinner (1957/1978), em li-

\footnotetext{
1 Endereço para correspondência: Prof. Lucas Ferraz Córdova, Cidade Universitária S/N - Caixa Postal 549, CEP 79070-900 - Campo Grande - MS. Email: cordovalf@gmail.com
} 
nhas gerais, em sete principais classes de operantes: mando, tato, ecóico, cópia, intraverbal, textual e tomar ditado - que são distinguidas pelas variáveis controladoras e pela topografia da resposta.

A definição de dois operantes verbais torna-se importante para o presente estudo, a de mando e de tato. O mando é definido como "um operante verbal em que a resposta é reforçada por uma conseqüência característica e está, portanto, sob o controle funcional de condições relevantes de privação ou estímulo aversivo" (Skinner, 1957/1978, p. 56). Dessa forma, o mando pode ser identificado como um operante verbal que constitui uma relação funcional em que a forma (ou topografia) da resposta é determinada por uma conseqüência específica, não tendo uma relação direta, como no caso dos demais operantes, com um estímulo discriminativo. Michael (1982), ao realizar a distinção entre as funções discriminativas e motivacionais do estímulo, retoma o uso do termo operação estabelecedora (OE) apresentado inicialmente por Keller e Schoenfeld (1950). Segundo Michael (1988), operação estabelecedora é "um evento ambiental, operação ou condição do estímulo que afeta o organismo pela alteração momentânea do efeito reforçador de outros estímulos e a freqüência de ocorrência de uma parte do repertório do organismo para aqueles eventos como conseqüência" (p. 3). A partir dessa revisão, a definição de mando seria, então, um operante verbal em que uma reposta particular é reforçada por uma conseqüência específica e está sob o controle funcional de uma operação estabelecedora relevante para tal conseqüência (Michael, 1993). Já o tato, como definido por Skinner (1957/ 1978), é "um operante verbal, no qual uma resposta de certa forma é evocada (ou pelo me- nos reforçada) por um objeto particular ou um acontecimento ou propriedade do objeto ou acontecimento" (Skinner, 1957/1978, p. 108). $\mathrm{O}$ tato pode ser identificado como um operante verbal que constitui uma relação funcional em que a forma (ou topografia) da resposta é controlada por um estímulo antecedente não-verbal e mantida por um reforço genérico. Ao se comparar as relações funcionais de tato e mando, tem-se que no tato a topografia ou forma da resposta está vinculada à presença do objeto ou sua propriedade (por exemplo, o sabor do sorvete). Diferentemente, o mando depende de uma operação estabelecedora, como uma privação. Reforço não-específico fortalece e mantém a respostas do tato, mas não determina o tipo de resposta que foi emitida anteriormente ao reforço; a forma do tato depende do estímulo discriminativo não-verbal antecedente. No caso do mando, reforço específico é a variável controladora principal da forma da resposta (Skinner, 1957/1978).

Uma importante implicação de se entender o comportamento verbal enquanto comportamento operante é a idéia de independência funcional entre operantes verbais. Em uma análise funcional do comportamento verbal, a busca por relações funcionais entre a resposta e as variáveis ambientais que a controlam deve ser realizada de forma independente para cada resposta. Isto porque, uma mesma topografia de resposta pode ser função de diferentes variáveis ambientais, e dessa forma, ser identificada em diferentes operantes verbais. Uma criança pode emitir a resposta verbal "água" sob o controle de um estímulo discriminativo, sendo a resposta definida como um tato, ou pode essa mesma topografia de resposta estar sob o controle de uma operação estabelecedora, já nesse caso a resposta seria definida como um mando. 
A idéia de independência funcional entre os operantes faz sentido a partir de uma análise funcional que explicita as variáveis distintas que controlam cada operante e enfatiza a análise do contexto em que o comportamento ocorre. Como dito anteriormente, operantes verbais diferentes possuem variáveis controladoras diferentes. Skinner (1957/1978) sugere então, a despeito de qualquer similaridade topográfica, que os operantes verbais são funcionalmente independentes entre si. A aquisição da topografia de uma resposta verbal em um operante verbal não resulta no seu uso automático em diferentes operantes. Isso porque o que é aprendido ao se adquirir uma resposta verbal, não é a emissão de uma determinada palavra ou o significado intrínseco a ela, e sim uma relação funcional, ou seja, a emissão de uma dada resposta na presença das variáveis ambientais necessárias. Com isso, é de se supor que uma criança que aprendeu uma certa topografia de resposta num dado contexto funcional não seja capaz de emitir essa mesma topografia de resposta quando defrontada com diferentes variáveis ambientais, pois a criança não apresentaria esse padrão de resposta sob o controle das novas variáveis em seu repertório comportamental sem que tenha passado por um treino.

Estudos empíricos sobre independência funcional surgem de forma mais significativa na literatura a partir do fim da década de 60 (Guess, 1969). Em sua grande maioria, os estudos com o foco na independência funcional entre operantes verbais se caracterizam por inicialmente estabelecer uma determinada topografia de resposta com uma função específica (e.g. mando, tato, intraverbal) e testar se esse treino inicial levaria colateralmente (sem treino específico) à emissão destas respostas verbais sob o controle de variáveis características de outros operantes verbais (Hall \& Sundberg, 1987; Lamarre \& Holland, 1985; Twyman, 1996). Com base nesses estudos busca-se apoio empírico a proposta feita por Skinner (1957/1978). Contudo, os primeiros estudos dentro dessa tradição (Cuvo \& Riva, 1980; Guess, 1969; Guess \& Baer, 1973; Lee, 1981) visavam principalmente investigar um outro tipo de relação envolvendo o comportamento verbal: a relação existente entre os repertórios de ouvinte e de falante. Esses dois repertórios também podem ser entendidos como funcionalmente independentes. O comportamento verbal (i.e. falante) com uma determinada topografia e o comportamento não verbal controlado por um estímulo verbal (i.e. ouvinte) com essa mesma topografia são também caracterizados por constituírem relações funcionais distintas.

Lee (1981) investigou a relação entre os repertórios de ouvinte e falante. Para o repertório de falante, um objeto era colocado à direita ou à esquerda de outro objeto. A resposta treinada era dizer "na direita" ou "na esquerda" dependendo da posição do objeto. O repertório de ouvinte era colocar um objeto à esquerda ou à direita de outro, dependendo do comando do experimentador. Seus resultados mostraram que o treino inicial com relações não-verbais (o colocar - repertório de ouvinte) não levava ao surgimento colateral das relações verbais, mas o oposto ocorria. Depois que os participantes eram treinados tanto nas relações verbais quanto nas não-verbais, as mudanças reforçadas no repertório do falante levaram a mudanças colaterais no repertório de ouvinte, mas o oposto não ocorreu. Portanto, a transferência foi unidirecional e relacionada aos repertórios iniciais dos participantes. A autora concluiu que quando a transferência espontânea 
ocorria, esta era devido a mudanças no controle de estímulos para respostas já presentes nos repertórios dos participantes e não à dependência entre os repertórios de falante e ouvinte. A autora chegou a essa conclusão não somente com seus próprios dados, mas fazendo uma reanálise dos dados de Guess e Baer (1973) e de Whitehurst (1977), que também mostraram que os participantes que apresentaram dependência tinham demonstrado os respectivos repertórios de forma aleatória e não consistente na linha de base.

Lamarre e Holland (1985) usaram um método muito semelhante ao de Lee (1981), com o objetivo de investigar a relação entre mandos e tatos. Ressalta-se que ambos operantes são repertórios do falante. Os pesquisadores queriam averiguar se treinando uma resposta verbal em um contexto funcional de tato, esta apareceria espontaneamente quando as contingências eram de mando. Para tanto eles recrutaram nove participantes com idades que variavam de 3 anos e 5 meses a 5 anos. Os participantes de número 1 a 4 receberam inicialmente treino de mando e foram testados para o surgimento colateral de tatos. Depois eles receberam o treino de tato e foram testados na manutenção do repertório de mando. Os participantes 5 a 9 receberam primeiro o treino de tato e foram testados para averiguar o surgimento colateral de mandos; em seguida, receberam treino de mandos e testaram a manutenção de tatos.

No treino de mando, o experimentador colocava um objeto no centro da mesa e pedia para a criança mandar o experimentador colocar outro objeto "à esquerda" ou "à direita" do objeto um. A obediência do experimentador foi vista como o reforço para o mando da criança. Para averiguar se as crianças estavam realmente discriminando a posição dos objetos, o experimentador pedia para elas dizerem se ele tinha colocado o objeto no lugar certo ou não, pois em algumas tentativas o experimentador colocava o objeto na posição oposta à requerida. No treino de tato, o experimentador colocava um objeto no centro da mesa e outro à esquerda ou à direita do primeiro. Ele então perguntava à criança "onde está o [objeto dois]?"; esta tinha que responder "à esquerda" ou "à direita" do objeto um. Os acertos eram reforçados e os erros corrigidos. Os testes seguiam o mesmo procedimento dos treinos só que sem reforçamento. Depois dos treinos nos dois repertórios, os participantes recebiam treino do repertório inicial, só que em posição invertida - treino do repertório invertido (esquerda virava direita e direita virava esquerda). Testava-se o surgimento colateral da reversão do outro repertório.

Os resultados mostraram que, para todos os participantes, a aquisição de mandos e tatos foi funcionalmente independente. Os quatro participantes que foram treinados a mandar não apresentaram tato colateral. Os cinco participantes que aprenderam a tatear não apresentaram os mandos colaterais. Ou seja, aprender uma resposta verbal como um operante não resultou no aparecimento dessa mesma resposta verbal em outro repertório. Nos treinos de repertórios invertidos, seis dos nove participantes não inverteram o outro repertório. Dos três participantes que inverteram o repertório, um inverteu o tato depois de aprender o mando invertido e dois inverteram o mando depois de receber treino de tato invertido. Ressalta-se que seis dos participantes não inverteram o segundo repertório mesmo depois de terem passado por um treino em ambos os repertórios, e as respostas verbais serem idênticas para os dois 
repertórios. Os achados do estudo corroboram a proposição de Skinner de que os diferentes operantes verbais são funcionalmente independentes - nesse caso específico, mandos e tatos.

$\mathrm{O}$ presente estudo tem como objetivo investigar a relação entre os operantes verbais tato e mando com a mesma topografia de resposta, durante o processo de aquisição do repertório verbal. De forma mais específica, o estudo buscou investigar se o treino de uma topografia de resposta verbal em um determinado operante é suficiente para produzir a emissão dessa mesma topografia em outro operante verbal. Buscou ainda investigar se ordem de treino (i.e. treino de mando - teste de surgimento colateral de tato; treino de tato - teste de surgimento colateral de mando) exerce alguma diferença sobre o desempenho dos participantes. Para tanto, replicou-se o estudo de Lamarre e Holland (1985), com algumas pequenas alterações, principalmente no que diz respeito ao equipamento e material. Tais alteraçóes foram realizadas com o intuito de minimizar o efeito de possiveis variaveis intervenientes sobre o estudo original, com isso buscou-se somar ao corpo de dados sobre a independência funcional entre operantes verbais.

\section{MÉTODO}

\section{Participantes}

Participaram do estudo dez crianças, nove do sexo feminino e uma do sexo masculino, com idades entre 2 anos e 6 meses e 4 anos e 5 meses, os pais de todas assinaram o consentimento livre esclarecido. Nenhuma criança apresentava história de problemas de desenvolvimento ou diagnósticos psiquiátricos, nem se encontrava em processo de alfabetização.

\section{Local, equipamento e materiais}

$\mathrm{O}$ experimento foi realizado na creche Programa Infanto-Juvenil (PIJ) localizada no campus da Universidade de Brasília.

$\mathrm{O}$ aparato experimental construído em forma de casa, com isolamento acústico foi colocado dentro das instalações da creche num local isolado das salas de aula. A casa tinha 240 $\mathrm{cm}$ de comprimento, $120 \mathrm{~cm}$ de largura e 180 $\mathrm{cm}$ de altura (Figura 1).
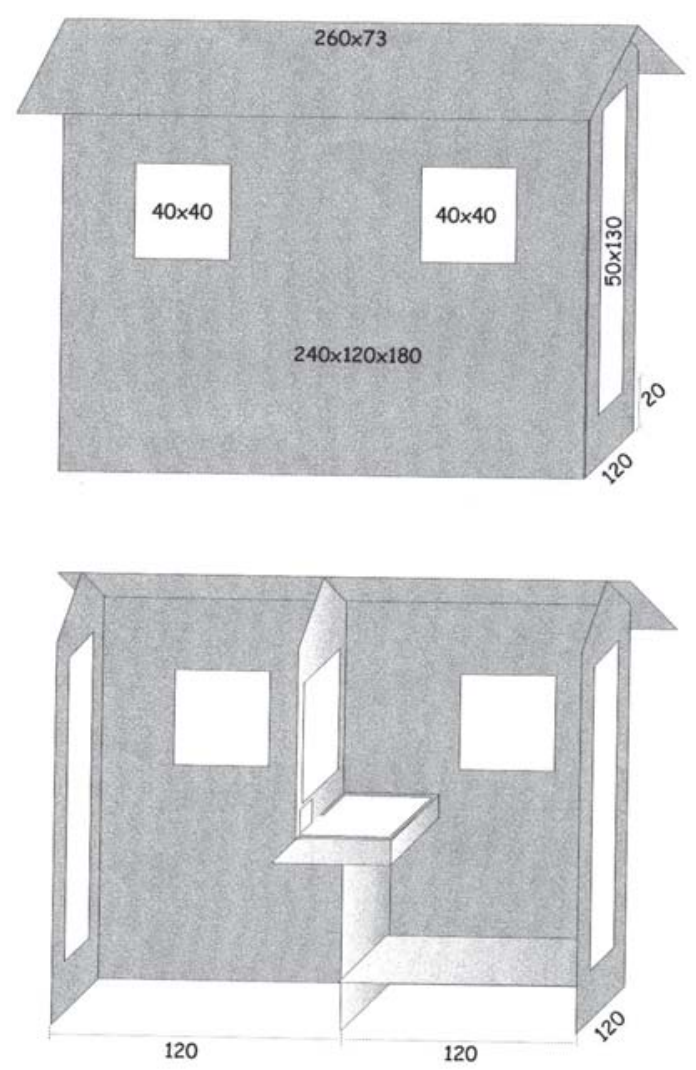

Figura 1. Representação esquemática do aparato experimental.

A casa dividia-se em dois espaços distintos, completamente separados um do outro. A primeira parte consistia no local da interação das crianças com os estímulos experimentais. Esse pedaço da casa tinha um balcão com dimensões de 120 × $40 \mathrm{~cm}$, feito de madeira, com 
uma superfície de fórmica branca e lisa, onde os bonecos em forma de bichos (estímulos experimentais) deslizavam. Acima do balcão, existia um espelho unilateral com dimensóes de 80 x $50 \mathrm{~cm}$. No lado esquerdo do balcão, situava-se uma casinha de brinquedo com uma abertura na lateral por onde os bonecos entravam e saiam. No lado direito do espelho, a aproximadamente $30 \mathrm{~cm}$ de altura do balcão, havia uma abertura de acrílico por onde fichas (reforçadores) caíam dentro de um pote de plástico transparente posicionado no balcão. Nesse local se encontrava o Experimentador 1.

A segunda parte do aparato experimental consistia no ambiente operacional, onde um dos experimentadores manipulava os bonecos e entregava os reforços através da abertura de acrílico. Nessa área, podia-se observar a criança e o outro experimentador através do vidro coberto, sem ser visto pelo participante. Do lado direito da divisória havia uma abertura por onde introduzir e retirar os bonecos. Do lado esquerdo havia a abertura para a entrega de fichas. Abaixo do vidro, o balcáo era vazado para que o experimentador pudesse manipular os bonecos através de imãs. Nesse local se encontrava o Experimentador 2.

Para estímulos experimentais utilizaramse seis pares de bonecos de plástico em forma de bichos conhecidos, com a base imantada para que pudessem ser manipulados com um imã. Os pares de bichos foram: cachorro e galinha, panda e carneiro, cavalo e vaca, porco e coelho, bode e urso, e hipopótamo e jacaré apresentados sempre nessa ordem.

Utilizaram-se fichas de plástico coloridas que eram trocadas por balas, pirulitos e brinquedos ao final de cada sessão. As respostas das crianças foram registradas em protocolos de papel com lápis e foram gravadas, com um gravador de áudio, em fitas cassetes.

\section{Procedimento}

As respostas verbais treinadas e testadas consistiam em palavras sem sentido LET e ZUT que substituíram as respostas já estabelecidas na comunidade verbal "esquerda" e "direita", respectivamente. No caso do tato, diante da estimulação verbal "Onde está o (nome do boneco)?" apresentada pelo experimentador, o participante deveria tatear a posição relativa de um boneco em relação a outro (i.e. "No LET/ ZUT do <nome do outro boneco>" ou somente "No LET/ZUT"). No caso do mando, diante da estimulação verbal "Para onde você quer que o <nome do boneco> vá?", o participante deveria mandar "Vai para o LET/ZUT do $<$ nome do outro boneco>" ou apenas "Vai para o LET/ZUT". No mando, o participante deveria ainda responder se o boneco se moveu corretamente, já que em uma de cada quatro tentativas o boneco era movido para a posição contrária à mandada.

O experimento foi dividido em três fases experimentais, cada qual consistindo em dois treinos de um operante e os respectivos testes do surgimento colateral da resposta verbal no outro repertório.

Os participantes foram divididos em dois grupos diferenciados pela ordem de treino. $\mathrm{O}$ Grupo 1 era composto por quatro crianças e o Grupo 2 por seis crianças. Para o Grupo 1, a ordem das fases foi a seguinte: Fase 1. treino de mando padrão, teste de tato padrão; Fase 2. treino de tato padrão, teste de manutenção de mando padrão; Fase 3. treino de mando invertido, teste de tato invertido. Para o Grupo 2, segue a ordem das fases: Fase 1. treino de tato padrão, teste de mando padrão; Fase 2. treino de mando 
padrão, teste de manutenção de tato padrão; Fase 3. treino de tato invertido, teste de mando invertido. A Tabela 1 apresenta as fases experimentais propostas para os dois grupos.

Utilizaram-se dois pares de bonecos em cada fase. Realizava-se o treino do operante padrão e posterior teste do operante colateral com o primeiro par de bonecos e em seguida era refeito o procedimento da respectiva fase com o segundo par de bonecos. A criança só passava para a condição seguinte quando ela atingia os critérios estabelecidos.

Antes de iniciar as fases experimentais, algumas respostas foram exigidas como pré-requisito, para que a dificuldade em discriminar os bonecos ou pronunciar as palavras LET e ZUT não fossem um complicador para a emissão das respostas de mando e tato a serem treinadas. Para tanto, os participantes passaram por um treino ecóico das palavras LET e ZUT, bem como foram treinados e testados a apontar e nomear cada membro do par de bonecos em treino em cada fase.

Pré-treinos: nomear e ecoico. O treino de nomear consistiu em ensinar a criança o nome dos animais, perguntando o nome e pedindo para ela apontar para o bicho correspondente. A título de exemplo, os estímulos cachorro e galinha serão usados para explicar o procedimento com os pares de bonecos, mas cabe ressaltar que estes mudavam dependendo da fase de experimento. No treino de apontar, o Experimentador 1 pedia para a criança: "Aponte para o Cachorro (Galinha)". Reforçavam-se os acertos e corrigiam-se os erros com o Experimentador 1 dizendo, "Não, esse é o Cachorro (Galinha)" apontando para o bicho certo. Se a criança não apontasse para nenhum animal, o experimentador demonstrava o comportamento com o próprio dedo e depois ajudava a criança a desempenhar o movimento, até que ela fizesse sozinha. $\mathrm{O}$ critério para encerrar este treino de apontar era a emissão de quatro respostas corretas consecutivas, duas para cada animal. No treino de nomear, o Experimentador 1 apontava para o Cachorro (Galinha) e perguntava “Quem é este?”. A criança deveria emitir a resposta vocal "Cachorro (Galinha)” (aceitavam-se aproximaçōes); respostas corretas eram reforçadas e respostas incorretas eram corrigidas e modeladas. $\mathrm{O}$ critério para este treino de nomear era de quatro respostas

Tabela 1

Descrição dos participantes (nomes fictícios) e fases experimentais para cada grupo.

\begin{tabular}{cccccc}
\hline Grupo & Participantes & Idade & Fase 1 & Fase 2 & Fase 3 \\
\hline 1 & Pilar & 3 a $7 \mathrm{~m}$ & treino de & treino de tato & treino de \\
& Nina & 3 a $7 \mathrm{~m}$ & mando pa- & padrão/teste & mando inverti- \\
& Marta & 4 a $1 \mathrm{~m}$ & drão/teste de & de manuten- & do/teste de \\
& Joana & 4 a $4 \mathrm{~m}$ & tato colateral & ção de tato & tato invertido. \\
& Fred & 2 a $6 \mathrm{~m}$ & treino de tato & treino de & treino de tato \\
& Vera & 2 a $10 \mathrm{~m}$ & padrão/teste & mando & invertido/teste \\
& Maria & 2 a $10 \mathrm{~m}$ & de mando & padrão, teste & de mando \\
& Carla & 3 a $5 \mathrm{~m}$ & padrão & de manuten- & invertido \\
& Helena & 3 a $6 \mathrm{~m}$ & & ção de tato & \\
& Eliza & 4 a $5 \mathrm{~m}$ & & & \\
\hline
\end{tabular}


corretas consecutivas, duas para cada animal. Para cada par de animais introduzidos no experimento, repetia-se o treino de nomear.

$\mathrm{O}$ treino ecoico consistiu em verificar a capacidade da criança pronunciar "LET" e “ZUT". O Experimentador 1 pedia para a criança olhar para ele e repetir: "Diga LET / ZUT”. A criança deveria vocalizar a sílaba requerida (aceitavam-se aproximações). Respostas corretas eram reforçadas e respostas incorretas eram corrigidas e modeladas. $\mathrm{O}$ critério nessa etapa era quatro respostas corretas consecutivas, duas para LET e duas para ZUT.

Treino de Tato Padrão. O Experimentador 2 movia a galinha para a esquerda ou direita do cachorro e, a princípio, o Experimentador 1 demonstrava para a criança, durante as quatro primeiras tentativas, o que ela deveria fazer: "a galinha está no LET / ZUT do cachorro” (dependendo de sua posição). Depois ele passava a vez para o participante e perguntava "Onde está a galinha?”. Quando a galinha estivesse à direita do cachorro, o participante deveria responder "No LET do cachorro" (ou somente "No LET"). Quando a galinha estivesse à esquerda, ele deveria responder "No ZUT do cachorro" (ou somente "No ZUT"). Respostas corretas eram reforçadas e respostas incorretas eram corrigidas e modeladas da seguinte forma: se a criança respondesse LET ou ZUT de forma trocada, o experimentador dizia, "Não, o cachorro está no LET / ZUT da galinha"; se a criança não emitisse nenhuma resposta verbal por até cinco segundos, o experimentador repetia a pergunta inicial; se o silêncio continuasse, pedia-se para a criança repetir "Diga, o cachorro está no LET / ZUT da galinha”, então, elogiava-se o acerto, mas a tentativa era marcada como erro. $\mathrm{O}$ critério para encerrar este treino era o acerto consecu- tivo de dois blocos de tentativas sem modelagem ou dicas do experimentador. Isso significava, quatro respostas corretas com a galinha se movimentando e quatro respostas corretas com o cachorro se movimentando.

\section{Treino de Mando Padrão.}

Experimentador 1 primeiro fazia uma demonstração de como a criança deveria mandar os bichos para receber o reforço: "cachorro, vá para o LET / ZUT da galinha.”. Isso era feito quatro vezes com o primeiro bicho do par. O experimentador ressaltava que, às vezes, o bicho errava de posição. Isso também era demonstrado: "não cachorro, você errou". Então, pedia-se para a criança mandar o cachorro para onde ela quisesse. A criança deveria mandar o cachorro para o "LET da galinha" ou para o "ZUT da galinha”. Quando isso ocorria, o Experimentador 2 movia o cachorro para a posição mandada pela criança. Uma em cada quatro tentativas, o experimentador 2 movia o bicho para a posição oposta à mandada. Em cada tentativa, o Experimentador 1 perguntava se o bicho tinha ido para onde foi mandado. Anotava-se o mando da criança e se ela discriminou corretamente a posição. A resposta só era considerada correta se a criança mandasse para o LET ou para o ZUT e discriminasse que o animal tinha de fato ido para onde foi mandado. Para classificar uma resposta verbal como mando, a conseqüência precisa ser específica à operação estabelecedora antecedente, caso contrário, não fica claro se a resposta verbal do participante é verdadeiramente um mando. Yamamoto e Mochizuki (1988) ressaltaram o cuidado necessário de averiguar a discriminação por parte da criança da conseqüência do mando. Por isso houve o cuidado no presente estudo de verificar se a criança estava discriminando se o bicho foi para o lugar mandado. 
Respostas corretas eram reforçadas. Respostas incorretas eram corrigidas e modeladas da seguinte forma: se a criança não emitisse nenhuma resposta verbal durante 5 segundos, a instrução inicial era repetida, caso continuasse o silêncio, o experimentador demonstrava dizendo "Diga, cachorro, vá para o LET / ZUT da galinha" e depois conseqüenciava o boneco dizendo "Diga, muito bem cachorro, você acertou!" ou "Não cachorro! Aí é o LET / ZUT da galinha, você errou!" (dependendo da situação). Se a criança mandasse para o LET ou ZUT, mas depois respondesse que o bicho tinha ido para a posição mandada quando este de fato não tinha, o experimentador dizia "Não, você mandou o cachorro ir para o LET / ZUT e ele não foi. Diga, você errou cachorro”. O critério para passar este treino era dois blocos consecutivos corretos, um com cada membro do par de animais, sem modelagem ou dicas do experimentador.

\section{Teste de Mando Padrão.} Experimentador 1 dizia que agora eles iam fazer uma coisa um pouco diferente, que agora era a vez da criança mandar o boneco ir para onde ela quisesse. Então, o experimentador dizia, "Diga a galinha onde você quer que ela vá". Se a criança mandasse para o LET ou para ZUT, o experimentador 2 movia o bicho para a posição pedida em $3 / 4$ das tentativas. Em um quarto das tentativas, o experimentador 2 colocava o bicho na posição errada. $\mathrm{O}$ experimentador 1 anotava o mando da criança e depois perguntava "A galinha foi para onde você mandou?" Esperava-se a resposta da criança ("Sim, ela foi" ou "não, ela errou" ou aproximaçôes nesse sentido) e anotava-se essa resposta. Caso a criança mandasse o bicho para outro lugar que não o LET ou ZUT, o bicho não se movia e o experimentador anotava o mando emitido no protocolo. Se a criança não emitisse nenhuma resposta verbal durante 10 segundos, anotavase o erro e repetia-se a instrução inicial. Cada vez que o Experimentador 1 emitia a instrução inicial, considerava-se isso como uma nova tentativa. A criança tinha quatro tentativas com cada bicho do par. As respostas não eram reforçadas, corrigidas ou modeladas.

Teste de Tato Padrão. O Experimentador 2 movia a galinha para a esquerda ou direita do cachorro e o Experimentador 1 perguntava à criança “Onde está a galinha?”. Quando a galinha estivesse à direita do cachorro, ela deveria responder "No LET do cachorro"; quando a galinha estivesse na esquerda, ela deveria responder "No ZUT do cachorro". Qualquer outro tipo de resposta, inclusive a não emissão de resposta verbal foi considerado erro. As respostas não eram reforçadas, corrigidas ou modeladas. Cada vez que o experimentador repetia a pergunta inicial, iniciava-se uma nova tentativa. A criança tinha quatro tentativas com cada bicho do par. Este teste foi conduzido para verificar se o operante anteriormente treinado permaneceu nos repertórios dos participantes.

Treinos de Tato Invertido e Testes de inversão do mando. Estes foram conduzidos exatamente como os treinos de tato padrão e testes do mando padrão, com a única diferença que as posições foram invertidas. $\mathrm{O}$ que antes era ZUT (esquerda) passou a ser LET e o que era LET (direita) passou a ser ZUT.

Treinos de Mando Invertido e Testes de inversão do Tato. Estes foram conduzidos exatamente como os treinos de mando padrão e testes de tato padrão, com a única diferença que as posições foram invertidas. $\mathrm{O}$ que antes era ZUT (esquerda) passou a ser LET e o que era LET (direita) passou a ser ZUT. 
Critério dos testes. Para dizer que a criança apresentou uma relação de dependência funcional entre operantes, determinou-se que a criança deveria obter, no mínimo, $75 \%$ de acerto (acertar no mínimo seis tentativas) nos testes que averiguavam a emissão do repertório colateral.

Confiabilidade dos Dados. Durante todas as sessões experimentais, as respostas dos participantes foram registradas em protocolos e gravadas em fitas de áudio para posterior transcrição. A transcrição de todos os testes foi feita por um observador não envolvido diretamente no projeto. Fez-se então uma comparação entre o protocolo escrito e a transcrição. Obtevese um índice de concordância entre observadores de 99,65\%, calculado através da fórmula: acordos X 100 / acordos + desacordos.

\section{RESULTADOS}

Apesar de não se poder categorizar as respostas dos participantes como "corretas" ou "incorretas", tais termos foram usados para identificar os padrōes de respostas apresentados. Nos treinos, "correto" equivale a respostas reforçadas e "incorreto aquelas não reforçadas. Nos testes, "correto" corresponde as respostas que indicam dependência funcional e "incorreto" aquelas que indicam independência funcional.

Todos os participantes, em ambos os grupos, atingiram o critério de quatro respostas corretas consecutivas no pré-treino treino de nomear e no pré-treino de apontar para os bichos. Cada vez que um par de bonecos era introduzido, verificava-se esse pré-requisito. Essa etapa do experimento era para a certificação de que as crianças conseguiriam distinguir os estímulos experimentais e tinham repertório de ouvinte para seguir as instruçôes do experimentador. Além disso, todos os participantes conseguiram ecoar as palavras LET e ZUT, atingindo o critério de quatro acertos consecutivos no início do experimento. Esses treinos não foram incluídos nos gráficos dos resultados.

\section{Grupo 1}

Como observados nas Figura 2 e 3, em que estão representados o número de acertos por blocos, respectivamente de quatro participantes e um participante, o número de tentativas durante os treinos de mando padrão da primeira Fase Experimental 1 para os membros do Grupo 1 variou entre 12 e 152 respostas com o primeiro par de bonecos e de 8 a 32 com o segundo par de bonecos. Com exceção da participante Pilar, que aumentou o número de tentativas do primeiro para o segundo par, todos os demais tiveram uma diminuição do número de tentativas no segundo par de bonecos igual ou superior a cento em relação ao treino com o primeiro par de bonecos. É importante ressaltar que as participantes Nina e Marta foram as que necessitaram do maior número de tentativas para atingirem o critério nos treinos. Durante os testes de surgimento colateral do operante tato, a participante Pilar não apresentou nenhuma resposta correta em nenhum dos dois pares de bonecos, a participante Nina teve sete respostas corretas no primeiro teste e quatro no segundo teste, Marta atingiu seis respostas corretas no primeiro teste e sete no segundo e, por fim, Joana não acertou nenhuma resposta no teste do primeiro par de bonecos e acertou todas as tentativas no teste do segundo par de bonecos.

$\mathrm{Na}$ Fase Experimental 2, onde foram realizados o treino de tato e teste de manutenção do mando, o responder das participantes se mostrou bastante variado. Durante os treinos com o primeiro par de bonecos, o número de 

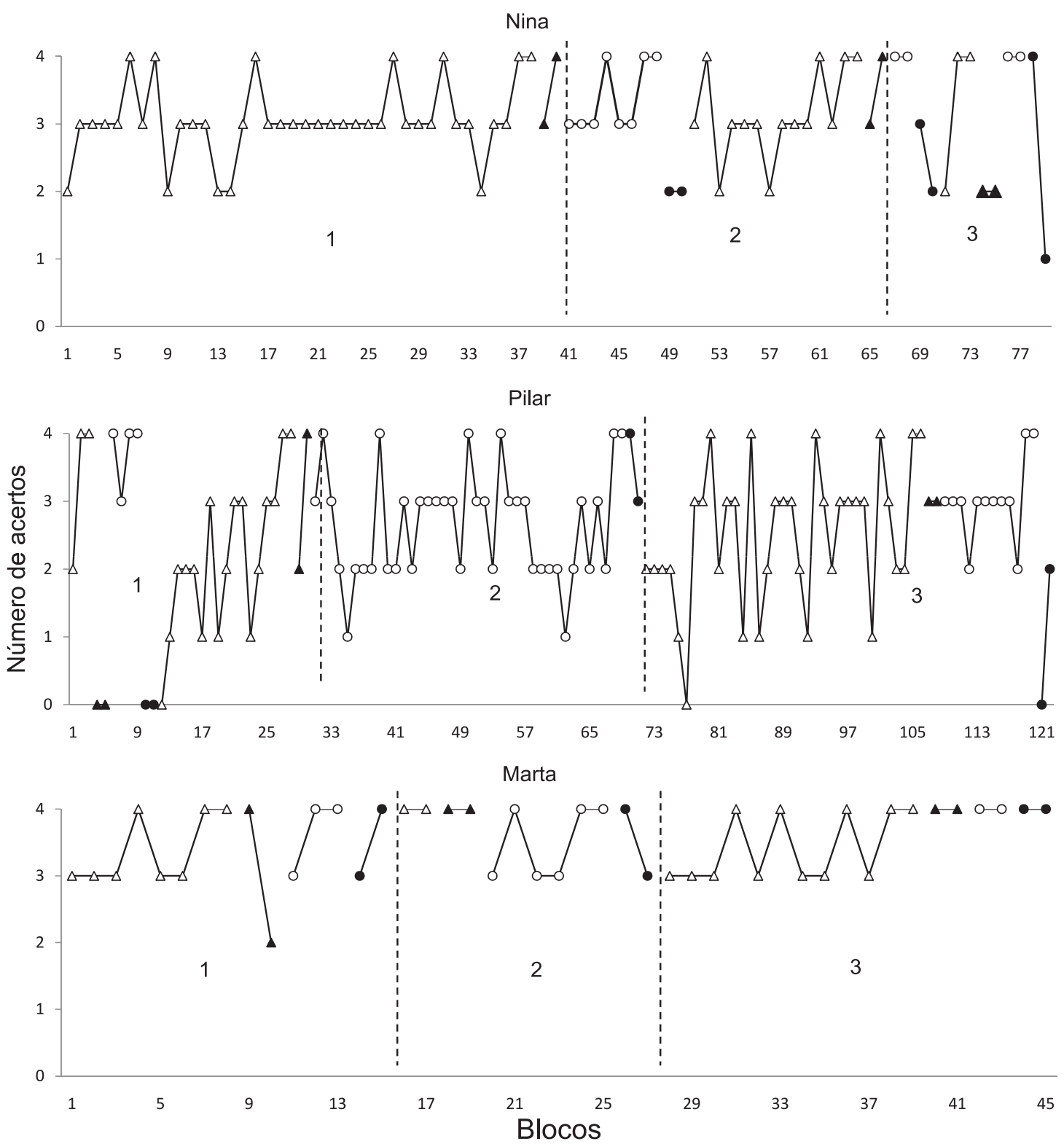

Figura 2. Número de acertos por bloco de tentativas durante as três fases do experimento (1 - treino de mando padrão/ teste de tato colateral; 2 - treino de tato padrão/teste de manutenção de mando; 3 - treino de mando invertido/teste de tato invertido) para um participante do Grupo 1. Triangulos representam o desempenho no primeiro par de bonecos. Circulos representam o desempenho no segundo par de bonecos. Símbolos vazios representam os treinos, símbolos cheios representam os testes.

tentativas variou de 8 a 68 respostas entre as participantes. No segundo par de bonecos essa variação foi de 8 a 160 tentativas. Em ambos os pares de bonecos, para a participante Pilar foi necessário maior número de tentativas para que o critério fosse atingido. As participantes
Nina e Joana diminuíram o número de tentativas para atingir o critério no segundo par de bonecos em relação ao primeiro par, já as participantes Pilar e Marta apresentaram aumento no segundo par em relação ao primeiro par. Durante os testes de manutenção de mando, a 


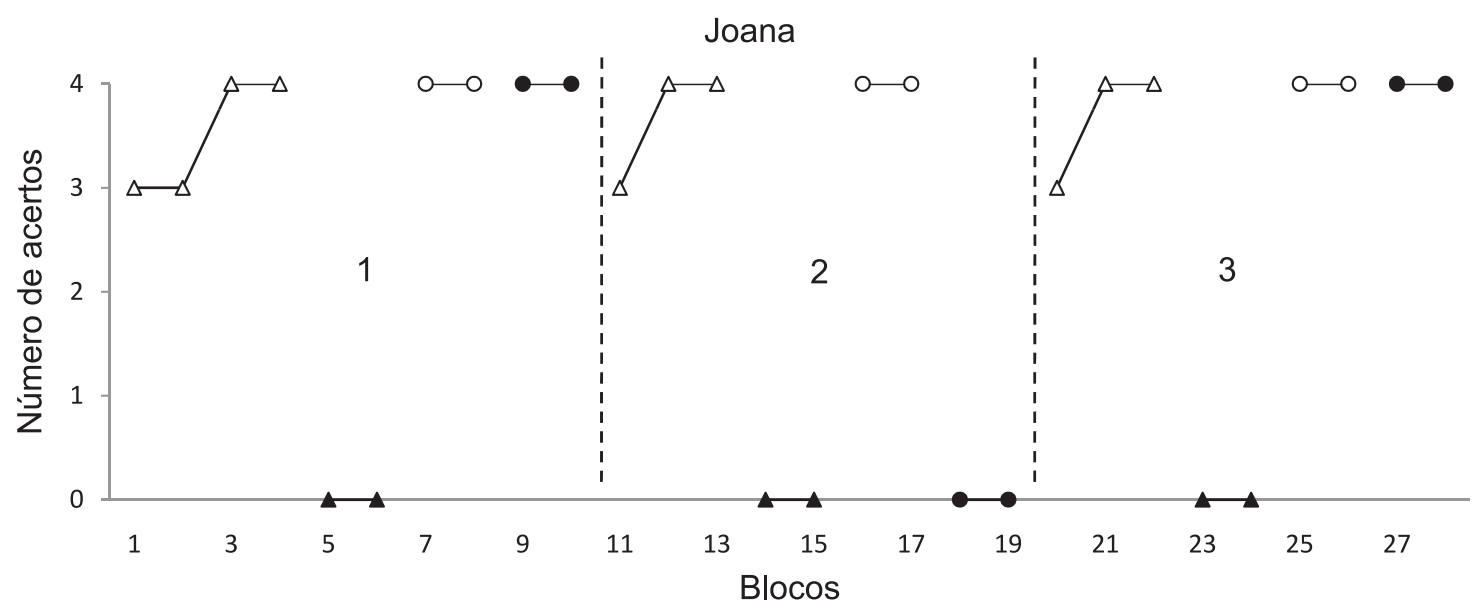

Figura 3. Número de acertos por bloco de tentativas durante as três fases do experimento (1 - treino de mando padrão/ teste de tato colateral; 2 - treino de tato padrão/teste de manutenção de mando; 3 - treino de mando invertido/teste de tato invertido) para um participante do Grupo 1. Triangulos representam o desempenho no primeiro par de bonecos. Circulos representam o desempenho no segundo par de bonecos. Símbolos vazios representam os treinos, símbolos cheios representam os testes.

participante Pilar teve duas respostas erradas no primeiro par de bonecos e apenas uma no segundo. Nina teve uma tentativa incorreta no teste com o primeiro par de bonecos, e três no segundo. A participante Marta apresentou apenas um erro no segundo teste. Já a participante Joana não demonstrou nenhuma resposta correta em nenhum dos dois testes.

$\mathrm{Na}$ Fase Experimental 3, durante o treino de mando invertido, a participante Pilar precisou de 134 tentativas com o primeiro par de bonecos e 48 tentativas com o segundo par. A participante Marta atingiu o critério de treino com 48 respostas no primeiro par e 8 no segundo. As participantes Nina e Joana precisaram ambas de 12 respostas no primeiro par e 8 no segundo. Vale notar que o critério foi atingindo no segundo par com um número menor de tentativas por todos os participantes. Durante o teste de inversão colateral do operante tato, Pilar teve seis respostas corretas no primeiro teste e duas no segundo, Nina acertou 4 e 5 respostas no primeiro e segundo teste respectivamente, Marta teve $100 \%$ de acerto em ambos os teste e Joana não apresentou resposta correta no primeiro par e acertou todas no segundo par.

\section{Grupo 2}

A partir da Figura 3 e Figura 4, pode-se observar os resultados dos Grupo 2. Durante o treino do primeiro par da Fase Experimental 1, treino de tato, os participantes do grupo apresentaram uma variação entre sujeitos no responder de 16 respostas (Carla) a 72 respostas (Fred). No segundo par de bonecos essa variabilidade cai, e fica entre 12 respostas (Vera; Maria e Carla) e 32 respostas (Helena). No teste de surgimento colateral do operante tato realizado com o primeiro par de bonecos, com exceção da participante Vera que apresentou cinco respostas corretas, os outros participantes não apresentaram respostas corretas. Já no segundo teste, Vera manteve as mesmas cinco respostas corretas, Fred apresentou uma resposta correta, Maria teve três de suas respostas carac- 
terizadas como corretas e os demais (i.e. Carla, Helena e Eliza) continuaram sem nenhuma resposta correta.

$\mathrm{Na}$ Fase Experimental 2, treino de mando e teste de manutenção de tato, com exceção da participante Maria, todos participante precisaram de um número maior de tentativas no treino com o primeiro par de bonecos do que com o segundo par. No primeiro treino, três participantes (i.e., Maria, Helena e Eliza) precisaram do número
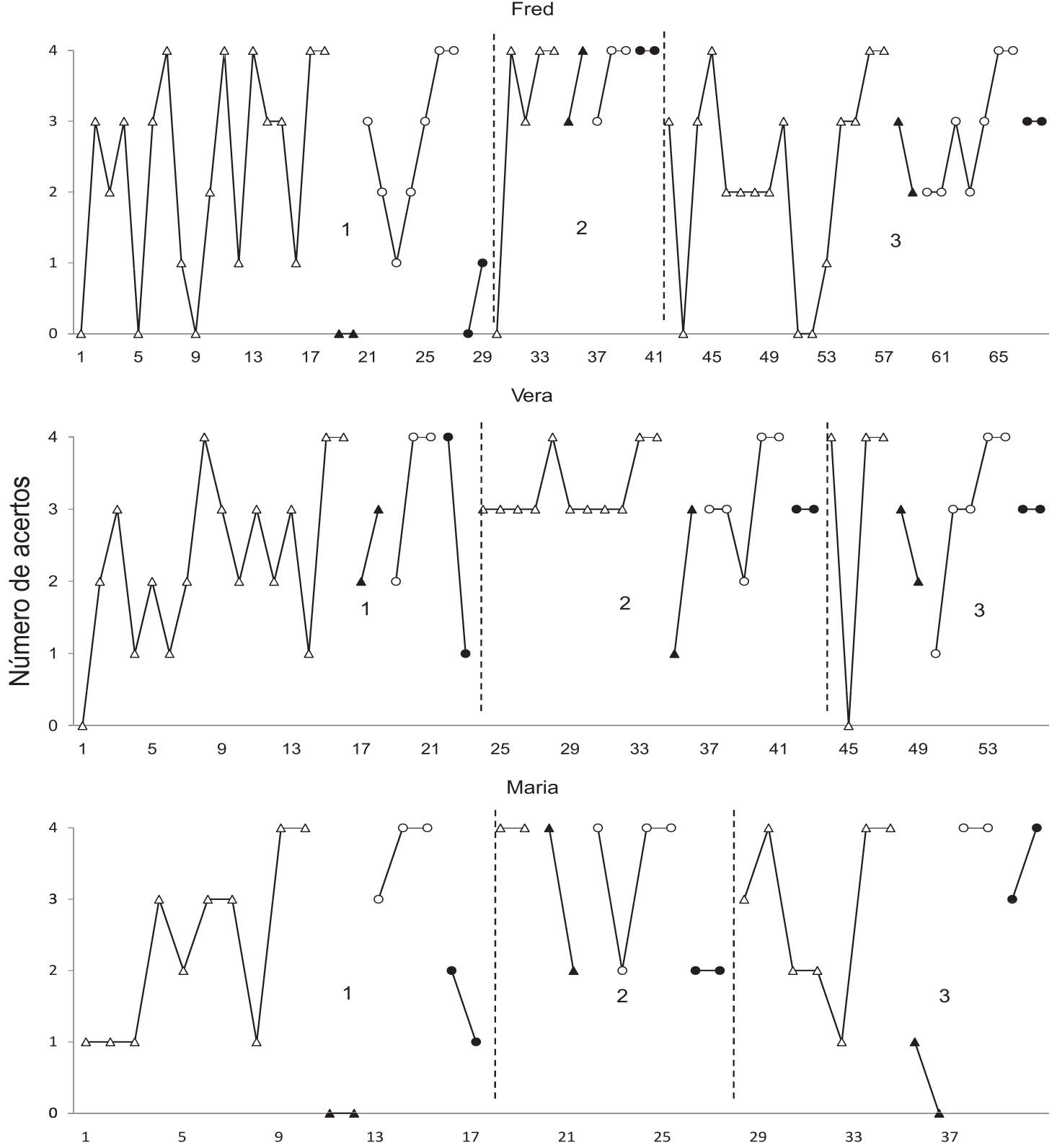

Blocos

Figura 4. Número de acertos por bloco de tentativas durante as três fases do experimento ( 1 - treino de tato padrão/teste de mando colateral; 2 - treino de mando padrão/teste de manutenção de tato; 3 - treino de tato invertido/teste de mando invertido) para três participantes do Grupo 2. Triangulos representam o desempenho no primeiro par de bonecos. Circulos representam o desempenho no segundo par de bonecos. Símbolos vazios representam os treinos, símbolos cheios representam os testes. 

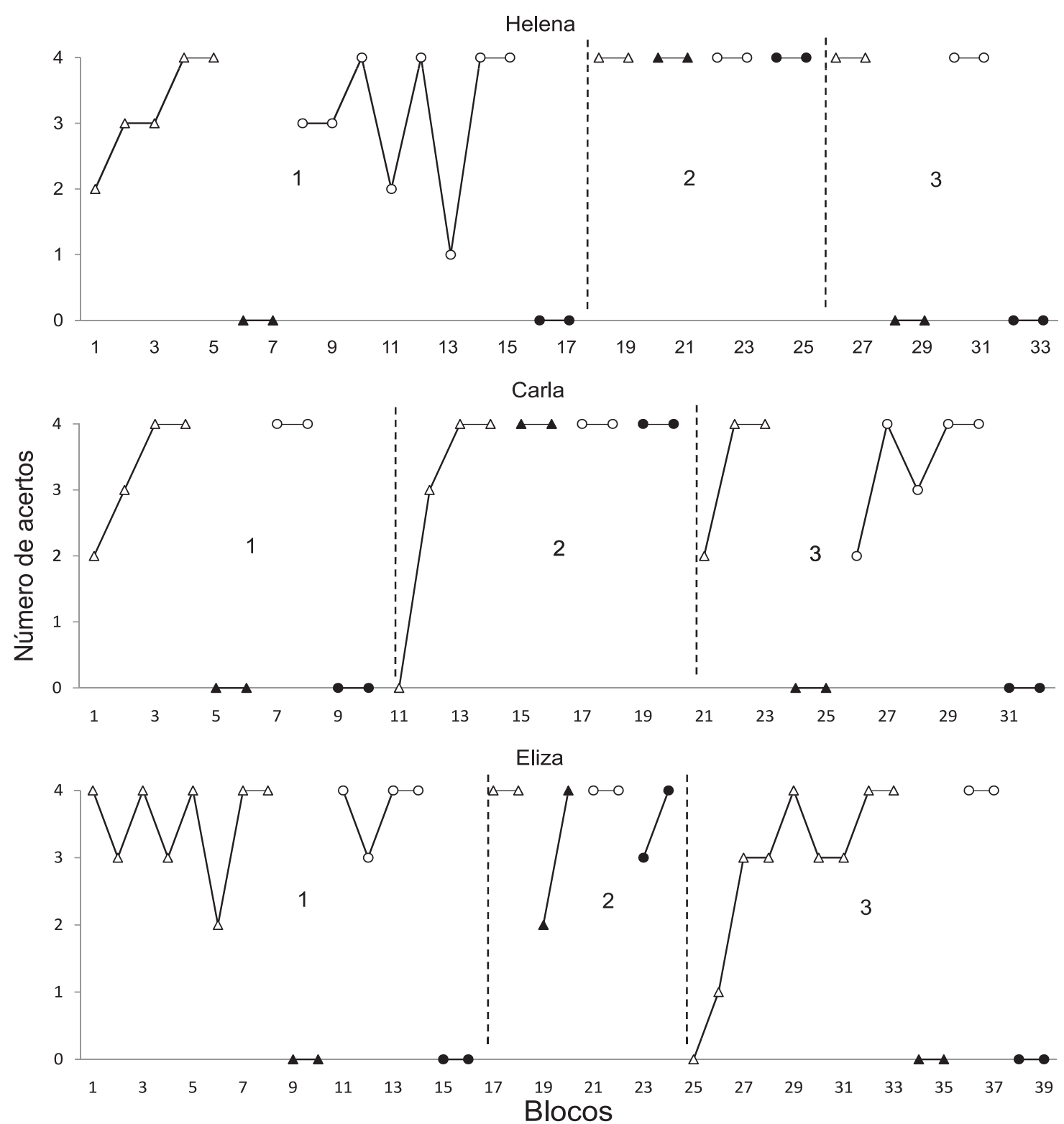

Figura 5. Número de acertos por bloco de tentativas durante as três fases do experimento ( 1 - treino de tato padrão/teste de mando colateral; 2 - treino de mando padrão/teste de manutenção de tato; 3 - treino de tato invertido/teste de mando invertido) para três participantes do Grupo 2. Triangulos representam o desempenho no primeiro par de bonecos. Circulos representam o desempenho no segundo par de bonecos. Símbolos vazios representam os treinos, símbolos cheios representam os testes.

mínimo de tentativas para atingir o critério (i.e. Já os demais, Fred, Vera e Maria precisaram de oito), os participantes Fred, Vera e Carla precisaram respectivamente de 20,44 e 16 tentativas no primeiro treino. No segundo par de bonecos, mais uma vez três participantes atingiram o critério com apenas oito tentativas (i.e. Carla, Helena e Eliza). 12,20 e 16 tentativas respectivamente. Carla, Helena e Eliza obtiveram $100 \%$ de acerto nos dois testes de manutenção de tato. Fred teve apenas um erro no primeiro par de bonecos, Vera acertou quatro respostas no primeiro par e seis no 
segundo, e Maria teve o desempenho contrário, seis no primeiro e quatro no segundo par.

$\mathrm{Na}$ Fase Experimental 3, treino de tato invertido e teste de inversão de mando apenas as participantes Vera e Carla precisaram de um treino mais extenso com o segundo par de bonecos do que com o primeiro. $\mathrm{O}$ número de tentativas no primeiro treino variou de 8 respostas (Vera) e 64 respostas (Fred). No segundo treino essa variação foi reduzida, sendo que três participantes (Maria, Helena e Eliza) precisaram de apenas oito tentativas. Vera e Carla precisaram de 20 tentativas para atingirem o critério para o término do treino. $\mathrm{O}$ participante Fred, mais uma vez, foi o que necessitou de um treino mais extenso (i.e. 28 respostas).

Os padrões de erros observados nos desempenhos dos participantes seguiram uma constância. Durante os testes da Fase Experimental 1, tanto para os participantes do Grupo 1 (i.e. teste de tato) quanto para os participantes do Grupo 2 (i.e. teste de mando) o padrão de erro mais observado foi a emissão de respostas genéricas, ou seja, no caso do mando, os participantes apontaram para a posição para onde o bone- co deveria ir, e no tato, apontaram a posição relativa do boneco, ao invés de emitir as respostas verbais LET e ZUT previamente aprendidas. No caso do teste de mando, observaram-se ainda alguns erros de consequenciação do movimento do boneco, onde na maioria das tentativas erradas o boneco se movia para a posição contraria a mandada pela criança que consequenciava esse movimento como correto. Na Fase Experimental 3, os erros de respostas genéricas foram observados em participantes de ambos os grupos, porém nessa fase foi observado um novo padrão de erro em que as crianças não invertiam o operante testado colateralmente ao operante treinado, em outras palavras, durante os testes, mantinham o responder padrão aprendido na Fase Experimental 2 independente da inversão das posições ocorrida na Fase 3 durante o treino.

A Tabela 2 ilustra, com base no critério estabelecido para o enquadramento do desempenho dos participantes, os padróes de dependência ou independência funcional entre os operantes verbais mando e tato em ambos os grupos. Pode-se verificar, com a análise da tabela, a preponderância de independência fun-

Tabela 2

Desempenho dos participantes durante as fases experimentais 1 e 2 .

\begin{tabular}{|c|c|c|c|c|c|}
\hline \multirow[t]{2}{*}{ Grupo } & \multirow[t]{2}{*}{ Participantes } & \multicolumn{2}{|c|}{ Fase Experimental 1} & \multicolumn{2}{|c|}{ Fase Experimental 3} \\
\hline & & Primeiro par & Segundo par & Primeiro par & Segundo par \\
\hline \multirow[t]{4}{*}{1} & Pilar & Independ. & Independ. & Depend. & Independ. \\
\hline & Nina & Depend. & Independ. & Independ. & Independ. \\
\hline & Marta & Depend. & Depend. & Depend. & Depend. \\
\hline & Joana & Independ. & Depend. & Independ. & Depend. \\
\hline \multirow[t]{6}{*}{2} & Fred & Independ. & Independ. & Independ. & Depend. \\
\hline & Vera & Independ. & Independ. & Independ. & Depend. \\
\hline & Maria & Independ. & Independ. & Independ. & Depend. \\
\hline & Carla & Independ. & Independ. & Independ. & Independ. \\
\hline & Helena & Independ. & Independ. & Independ. & Independ. \\
\hline & Eliza & Independ. & Independ. & Independ. & Independ. \\
\hline
\end{tabular}


cional entre os diferentes repertórios verbais. Todos os participantes, com exceção de Marta, apresentaram independência funcional em pelo menos duas das fases do experimento.

\section{DISCUSSÃO}

O estudo teve como objetivo principal investigar as relações entre tatos e mandos durante a fase de aquisição desses repertórios. De forma mais específica, buscou investigar se o treino de uma topografia de resposta verbal em um determinado operante é suficiente para produzir a emissão dessa mesma topografia em outro operante verbal. Buscou ainda investigar se a ordem de treino (i.e. treino de mando teste de surgimento colateral de tato; treino de tato - teste de surgimento colateral de mando) exerce alguma diferença sobre o desempenho dos participantes. Com o intuito de atingir tais objetivos, realizou-se uma replicação parcial do estudo de Lamarre e Holland (1985).

Os resultados obtidos no presente trabalho corroboram parcialmente a proposta de independência funcional entre operantes verbais apresentada por Skinner (1957/1978). Isto porque, apenas no grupo 2 , em que foi treinado tato e testado o surgimento colateral do mando, é que foi observado claramente um desempenho compatível com a noção de independência funcional. Já com os participantes do grupo 1 foi observado uma grande variabilidade tanto intra quanto entre sujeitos, sendo observado desempenho de independência e de dependência funcional entre os operantes verbais.

Em relação ao grupo 1, os dados obtidos no presente trabalho são inconclusivos no que diz respeito à independência ou dependência funcional entre mando e tato, isto porque dos quatro participantes do experimento, um (Mar- ta) apresentou dependência funcional, um (Pilar) apresentou independência funcional e dois (Nina e Joana) apresentaram independência funcional com um par de bonecos e dependência funcional com o outro par de bonecos, isso na primeira fase do experimento.

$\mathrm{Na}$ Fase Experimental 2, dois dos quatro participantes (Pilar e Marta) demonstraram manutenção do mando treinado na fase anterior. O sujeito Nina demonstrou manutenção do mando no teste com primeiro par de bonecos, já no segundo par de bonecos, o número de acertos foi muito próximo do acaso. O sujeito Joana não emitiu nenhuma resposta compatível com o padrão exigido durante os dois teste de manutenção de mando. $\mathrm{Na}$ terceira fase experimental, apenas uma das crianças (Marta) apresentou a inversão funcional do tato com os dois pares de bonecos. Um participante (Pilar) apresentou inversão com o primeiro par e outro participante (Joana) com o segundo par. E o participante Nina, apesar de apresentar respostas corretas em ambos os testes de inversão, não atingiu o critério estabelecido para que fosse considerado que houve inversão funcional do operante tato.

Para os membros do Grupo 2, na primeira fase do experimento (i.e. treino de tato padrão e teste de emissão de mando), todos os participantes apresentaram independência funcional. Apenas uma criança, Vera, mostrou indícios de dependência funcional. Ela mandou os dois pares de bonecos para as posiçôes, emitindo as respostas verbais LET e ZUT em cinco tentativas dentre as oito dos testes. Porém, esse desempenho não alcançou o critério estabelecido para considerar essa uma clara evidência de dependência funcional. $\mathrm{Na}$ última fase do experimento, três participantes apresentaram relaçôes de dependência enquanto os ou- 
tros três, de independência funcional entre os operantes verbais distintos (Fred, Vera e Maria demonstraram dependência após a inversão dos conceitos, enquanto que Carla, Helena e Eliza apresentaram independência).

A revisão dos dados da literatura aponta para duas direçôes supostamente opostas. De um lado, encontram-se os estudos em que a proposta de independência funcional foi corroborada (Carroll \& Hesse, 1987; Guess, 1969; Hall \& Sundberg, 1987; Lamarre \& Holland, 1985; Mousinho, 2004; Nuzzolo-Gomez \& Greer, 2004; Simonassi, 2004; Twyman, 1996). De outro lado, encontram-se os estudos em que o treino de um operante verbal foi condição suficiente para o surgimento da mesma topografia de resposta em um operante colateral, isto é, não diretamente treinado (Cuvo \& Riva, 1980; Guess \& Baer, 1973; Lee, 1981; Sazanov, 1998; Silva, 1996). O presente estudo apresenta dados em ambas as direções. No entanto, pode-se discorrer sobre algumas correlaçôes interessantes que apareceram nos dados que sugerem algum tipo de sistematização no que diz respeito às relaçôes de dependência e independência na fase de aquisição dos operantes verbais.

Os participantes de ambos os grupos que demonstraram dependência funcional, tanto na primeira fase experimental quanto na terceira, precisaram de um número superior de blocos de treino do que os participantes que demonstraram independência funcional. Lee (1981) discute os dados de dependência funcional com base na noção de controle de estímulo, isto é, os participantes que apresentam previamente ao experimento respostas verbais em diferentes operantes verbais (no caso do presente estudo, mando e tato), ao se depararem com o treino efetivo de uma nova resposta, (por exemplo, são reforçados ao emitirem a resposta verbal com função de mando "no LET"), estão sujeitos a uma modificação no controle do estímulo que pode levar a emissão de uma resposta já existente no repertório da criança em relação a esse novo estímulo, no caso, o tato. $\mathrm{O}$ maior número de blocos pode ter facilitado a mudança no controle de estímulos. Em outras palavras, o treino extenso do mando pode ter feito com que a resposta dos sujeitos ficasse sobre o controle da posição LET e ZUT enquanto estímulo discriminativo.

Uma outra característica em comum em ambos os grupos são os padrôes de erro. Em sua grande maioria, os erros apresentados pelos participantes durante os testes foi o de emissão de operantes (i.e. tatos e mandos) genéricos. Embora possam ser identificadas como tatos ou mandos, não se pode dizer que houve transferência de função com a emissão dessas respostas já que a topografia da resposta não foi igual à resposta treinada com o outro operante, não sendo assim consideradas como respostas de mando ou tato específico determinada pela situação experimental. Segundo Skinner (1957/ 1978), um mando genérico seria uma resposta que acompanharia outro comportamento, que, por sua vez, especificaria diferentes tipos de reforços, por exemplo, as respostas verbais "dá" ou "quero" são normalmente acompanhadas de respostas como apontar indicando um objeto. Este padrão comportamental poderia ser então observado em diferentes contextos. No caso do tato, as crianças podem aprender a emitir as respostas verbais "Aqui” e "Ali" acompanhadas do apontar. Essas são respostas verbais genéricas que normalmente geram um reforço quando seguem perguntas do tipo "Onde está a bola?” ou “Onde está a mamãe?”. Posteriormente, esse padrão comportamental se refinaria em respostas verbais mais específicas. 
A maior força dos mandos e tatos genéricos, encontrada nos repertórios dos participantes durante o experimento, pode ser decorrente de outras variáveis além da história de reforçamento da criança dentro da comunidade. As instruções durante os testes de mando foram bastante gerais, não especificando o que se esperava do participante (que ele mandasse o boneco para o LET ou ZUT). Essa escolha foi proposital, para que não houvesse nenhuma dica verbal que auxiliasse a transposição entre os repertórios de tato e mando, possibilitando verificar se ocorreria a emissão da resposta verbal nos testes do repertório colateral. Sabe-se, porém, que instruções verbais têm uma grande influência no comportamento humano (Galizio, 1979), logo, modificaçôes nas instruçôes poderiam influenciar no controle de estímulos e, portanto, o comportamento verbal da pessoa. Sugere-se a necessidade de um maior aprofundamento dessa variável em estudos futuros.

Como foi dito anteriormente, o presente estudo teve como um de seus objetivos avaliar se a ordem de treino interfere no desempenho de independência ou dependência funcional. Comparando os resultados dos grupos, pode se observar uma maior variabilidade nos resultados quando a ordem do treino é mando - tato (Grupo 1) em relação ao treino tato - mando (Grupo 2). Todos os participantes do grupo 2 demonstraram independência funcional, enquanto que com os membros do grupo 1 foi observado tanto independência funcional quanto dependência funcional. Essa diferença pode ser entendida ao se realizar uma análise da resposta de mando exigida no presente estudo.

Um ponto importante a ser levando é o fato de que a posição que servia de reforço para a resposta de mando foi a mesma que servia como estímulo discriminativo para o tato, o que pode ter feito com que a criança ficasse sob o controle de variáveis semelhantes em ambos os operantes. Disponibilizar fichas contingente às respostas corretas durante o treino de mando fez com que o reforço específico da verbalização do participante (i.e., movimentação do boneco para a posição mandada) não fosse o único reforço, em outras palavras, era disponibilizado para a criança um reforço genérico contingente à resposta definida como mando. Este reforço adicional aproximou ainda mais o operante mando do operante tato, ao qual o reforço genérico está conceitualmente relacionado. Essas características estão de acordo com as afirmações de Carroll \& Hesse (1987) e Twyman (1996) de que mandos e tatos iniciais estariam sob controle múltiplo de variáveis, o que facilitaria a generalização de topografias verbais entre diferentes operantes verbais. Um fator importante a ser considerado foi a dificuldade em se implementar uma operação estabelecedora efetiva para o operante mando. No presente estudo, as operações estabelecedoras não foram manipuladas de forma direta. Presumiu-se que o movimento dos bonecos seria motivador suficiente. Contudo, essa operação estabelecedora pode não ter sido forte o suficiente, e assim, ter influenciado de forma branda as respostas de mando dos sujeitos e com isso aproximado os operantes tato e mando.

$\mathrm{Na}$ literatura sobre a relação entre operantes verbais, alguns autores encontraram dados apontando para a independência funcional (Carroll \& Hesse, 1987; Guess, 1969; Guess \& Baer, 1973; Hall \& Sundberg, 1987; Lamarre \& Holland, 1985; Mousinho, 2004; Nuzzolo-Gomez \& Greer, 2004; Twyman, 1996), enquanto outros encontraram prioritariamente dependência funcional (Cuvo 
\& Riva, 1980; Lee, 1981; Silva, 1996; Whitehurst, 1977). Verifica-se uma polarização no posicionamento dos pesquisadores, onde dados que destoam da maioria acabam sendo explicados pela história do sujeito dentro da comunidade verbal. Talvez fosse mais interessante entender as relações na aquisição dos operantes verbais como um cone/espiral que começaria com independência funcional e progrediria, dependendo do grau de complexidade dentro dos diferentes repertórios e do aprendizado paralelo do comportamento de transposição, para a dependência funcional. Ou seja, nos primórdios da aquisição do comportamento verbal, haveria tanto uma baixa complexidade no repertório (como o choro que passa a adquirir função de mando) e a independência entre operantes distintos. A criança então começa a aprender a transpor certas respostas verbais entre operantes, possivelmente os mandos e tatos genéricos que têm controle de estímulos amplo. O comportamento de transposição então começa a ocorrer para respostas verbais mais complexas e específicas. Tanto a transposição quanto a complexidade dos repertórios estão intimamente relacionados. A principal variável que determina a progressão da aprendizagem torna-se, então, a experiência do indivíduo em interação com o ambiente e não necessariamente sua idade cronológica.

\section{REFERÊNCIAS}

Carroll, R. J. \& Hesse, B. E. (1987). The effects of alternating mand and tact training on the acquisition of tacts. The Analysis of Verbal Behavior, 5, 55-65.

Cuvo, A. J \& Riva, M. T. (1980). Generalization and transfer between comprehension and production: A comparison of retarded and nonretarded persons. Journal of Applied Behavior Analysis, 13, 315-331.
Galizio, M. (1979). Contingency-shaped and rulegoverned behavior: Instructional control of human loss avoidance. Journal of the Experimental Analysis of Behavior, 31, 53-70.

Guess, D. (1969). A functional analysis of receptive language and productive speech: Acquisition of the plural morpheme. Journal of Applied Behavior Analysis, 2, 55-64.

Guess, D. \& Baer, D. M. (1973). An analysis of individual differences in generalization between receptive and productive language in retarded children. Journal of Applied Behavior Analysis, 6, 311-329.

Hall, G. \& Sundberg, M. L. (1987). Teaching mands by manipulating conditioned establishing operations. The Analysis of Verbal Behavior, 5, 4153.

Keller, F.S. \& Schoenfeld, W.N. (1950). Principles of psychology. New York: Appleton-Century-Crofts.

Lamarre, J. \& Holland, J. G. (1985). The functional independence of mands and tacts. Journal of the Experimental Analysis of Behavior, 43, 5-19.

Lee, V. L. (1981). Prepositional phrases spoken and heard. Journal of the Experimental Analysis of Behavior, 35, 227-242.

Michael, J. (1982). Distinguishing between discriminative and motivational functions of stimuli. Journal of the Experimental Analysis of Behavior, 37, 149-155.

Michael, J. (1988). Establishing operations and the mand. The Analysis of Verbal Behavior, 6, 3-9.

Michael, J. (1993). Establishing operations. The Behavior Analyst, 16, 191-206.

Mousinho, L. S. (2004). Independência Funcional Entre Tatos e Mandos. Dissertação de Mestrado aprovada pelo Instituto de Psicologia, Universidade de Brasília.

Nuzzolo-Gomez, R. \& Greer, R. D. (2004). Emergence of untaught mands or tacts of novel adjective-object pairs as a function of instructional history. The Analysis of Verbal Behavior, 20, 63-76.

Sazanov, G.C. (1998). A independência funcional entre 
tactos e mandos e as operaçôes estabelecedoras condicionadas. Dissertação de Mestrado aprovada pelo Instituto de Psicologia da Universidade de Brasília.

Silva, W. C. M. P. (1996). Independência Funcional Entre Tactos e Mandos que Possuem a Mesma Estrutura Formal. Dissertação de Mestrado aprovada pelo Instituto de Psicologia, Universidade de Brasília.

Simonassi, L. (2004). Interdependência entre Aquisição e Produção de Mandos, Tatos e Intraverbais. Dissertação de Mestrado aprovada pelo Departamento de Psicologia, Universidade Católica de Goiás.

Skinner, B. F. (1957). Verbal Behavior. New Jersey: Prentice-Hall

Skinner, B.F. (1957/1978). Comportamento Verbal. (Ma- ria da Penha Villalobos. trad.). São Paulo: Editora Cultrix e Editora da Universidade de São Paulo.

Twyman, J. S. (1996). The functional independence of impure mands and tacts of abstract stimulus properties. The Analysis of Verbal Behavior, 13, 1-19.

Whitehurst, G. J. (1977). Comprehension, selective imitation, and the CIP hypothesis. Journal of Experimental Child Psychology, 23, 23-38.

Yamamoto, J. \& Mochizuki, A. (1988). Acquisition and functional analysis of manding with autistic students. Journal of Applied Behavior Analysis, 21, 57-64.

Recebido em 14 de janeiro de 2008 Aceito em 25 de agosto de 2008 